\title{
Comparison of Safety, Efficacy and Cost Effectiveness of Photoselective Vaporization with Bipolar Vaporization of Prostate in Benign Prostatic Hyperplasia
}

\author{
Priyanka Rai $^{a} \quad$ Alok Srivastava $^{\mathrm{b}} \quad$ Ishwar R. Dhayal ${ }^{\mathrm{b}}$ Sanjeet Singh ${ }^{\mathrm{b}}$ \\ aDepartment of Surgery; and 'bepartment of Urology and Renal Transplant, Dr. Ram Manohar Lohia Institute of Medical Sciences, \\ Gomtinagar, Lucknow, India
}

\section{Key Words}

Bipolar vaporization - Photoselective vaporization •

Benign prostatic hyperplasia $\cdot$ Cost effective

\section{Abstract}

Objectives: To compare bipolar vaporization of prostate (BPVP) with photoselective vaporization (PVP) of prostate in the surgical management of benign prostatic hyperplasia in terms of safety, efficacy and cost effectiveness. Methods: Data was analyzed retrospectively for patients who underwent either PVP or BPVP between August 2012 to July 2014 for prostate size $\leq 80 \mathrm{ml}$. Preoperative and postoperative period values along with details like operative time, blood loss, hospitalization days, catheter removal time, blood transfusion and etc., were noted down. International prostatic symptom score, quality of life scores, post void residue, and maximum flow rate were recorded preoperatively and postoperatively at each follow-up visit. Follow-up was performed at 1, 3, 6,12 and 18 months. Results: Similar preoperative characteristics were observed in all the study arms. Hemoglobin drop, transfusion rate, catheter time and hospital days were similar in both the groups. The follow-up data indicates sustainable significant improvement in international prostatic symptom score, quality of life, post void residue and maximum flow rate in both the groups. As expected the cost of the procedure was significantly more in PVP group as compared to BPVP group ( $p<0.01$ ). Neither group had severe perioperative complications and no blood transfusion was required in both the groups. Conclusion: Both PVP and

\section{KARGER}

(C) 2017 S. Karger AG, Basel

Fax +4161306 1234

E-Mail karger@karger.com

www.karger.com
Accessible online at: www.karger.com/cur
BPVP were safe and effective alternatives in men requiring surgery for benign prostatic hyperplasia including patients who were on anticoagulants. Additionally, BPVP has the advantage of being significantly cheaper and therefore it can be more useful in developing countries.

Copyright $\odot 2017$ S. Karger AG, Basel

\section{Introduction}

Transurethral resection of prostate (TURP) remains the gold standard procedure for managing benign prostatic hyperplasia (BPH), but it is also associated with numerous complications like transurethral resection syndrome, bleeding, infection and prolonged hospitalization. For these reasons, alternative techniques are being used in order to reduce complications as well as maintain the same efficacy as monopolar TURP. In recent years vaporization techniques for the prostate gland have become popular as they are easy to learn and have a short learning curve. Both photoselective vaporization (PVP) and bipolar vaporization of prostate (BPVP) are attractive and viable alternatives to the resection techniques. PVP provides real-time tissue ablation with excellent hemostasis, even in high-risk patients, and has gained increasing acceptance. PVP has efficacy comparable to that of TURP, but the main disadvantage is that it does not provide tissue for histologic examination and is an 
expensive procedure [1-3]. With the advancement in the bipolar technology, the popularity of transurethral electro-vaporization of the prostate has increased. A new development of this technique is the TURis ${ }^{\circledR}$-PVP using the Olympus ${ }^{\circledR}$ UES-40 Surgmaster generator (Olympus, Tokyo, Japan) and the "mushroom" or the plasma button electrode. The plasma-button alternative is characterized by reduced perioperative bleeding risk, shorter catheterization period and hospital stay, as well as satisfactory improvement in symptom scores and voiding parameters [4-7]. There are numerous studies comparing both PVP and BPVP with monopolar resection, but there is a lack of data comparing the two vaporization techniques with each other to find out the better alternative. Therefore, we did a retrospective comparative study between PVP and BPVP with special focus on functional results, complications and the cost effectiveness of both the procedures. To our knowledge this study is perhaps the first study comparing the two vaporization techniques.

\section{Methods}

Data was analyzed retrospectively for patients who underwent either PVP or BPVP at our institute between August 2012 and July 2014 for prostate size $\leq 80 \mathrm{ml}$. The primary endpoint of the study was to evaluate the null hypothesis that the tissue ablation capacity, blood loss, safety characteristics, postoperative recovery period, and follow-up features determined for a period of 18 months were similar subsequent to any of the 2 types of techniques. The study was approved by the Local Ethics and Research Committee of Dr. Ram Manohar Lohia Institute of Medical Sciences, Lucknow. All patients were preoperatively evaluated with digital rectal examination, international prostatic symptom score (IPSS), quality of life (QoL) score, maximum urinary flow rate (Qmax), prostate-specific antigen level (PSA), prostate volume measured by transrectal ultrasonography (TRUS). The inclusion criteria were Qmax of $<15 \mathrm{ml} / \mathrm{s}$, IPSS $>12$, failure of medical therapy, and prostate volume of $\leq 80 \mathrm{ml}$. Exclusion criteria was prostate volume $<30 \mathrm{ml}$, documented or suspected prostate cancer, neurogenic bladder, bladder stone or diverticula, urethral stricture, and previous history of prostate surgery. For statistical analysis, the patients in either PVP or BPVP arms were further divided into 4 subgroups namely $\mathrm{A} 1$ and $\mathrm{B} 1$ for PVP and BPVP in prostate volume $30-60 \mathrm{ml}$, and A2 and B2 for PVP and BPVP in volume 60-80 $\mathrm{ml}$, respectively.

BPVP and PVP were done by two and one experienced urologists, respectively. BPVP was performed using the special "mushroom" tip electrode and the Olympus Surg-Master UES-40 bipolar generator. The electrode displaying a plasma corona on its surface was gradually moved over the prostatic tissue (the "hovering" technique), thus producing a virtually bloodless vaporization at 280-320 W. After placing the electrode in the continuous working sheath, vaporization is begun at the bladder neck between the 4 o'clock and 8 o'clock position back to the verumontanum. In this step special care is taken to make sure that direct visulaization of the button electrode is maintained at all times so that the verumontanum, external sphincter and the ureteral orifices are not damaged. Vaporization was safely done in both the forward and backward motions of the button which further increases the efficiency of the procedure. Once the posterior aspect of the prostate is vaporized adequately, the lateral lobes were vaporized starting from the bladder neck back to the level of the bladder neck but not beyond. After the lateral lobes were dealt with, the anterior tissue was vaporized if at all needed. Coagulation of any hemorrhagic sources was practically concomitant during vaporization, while hemostasis of larger vessels was achieved by reducing the power of the generator to $120-140 \mathrm{~W}$. For PVP a $120 \mathrm{~W}$ HPS generator and a $600 \mu$, side firing laser fiber having a wavelength of 535 $\mathrm{nm}$, was used. For vaporization the fibre was moved in a "Paint brush" fashion and was kept in near contact with the tissue. Coagulation was done by moving the fibre slightly away (defocusing) or by reducing the power to $30-50 \mathrm{~W}$. Saline was used for continuous irrigation. In all cases in both the arms a $22 \mathrm{~F}$ Foley catheter was placed at the end of the procedure. Irrigation was continued for 2 hours postoperatively and was stopped once the urine was clear. The catheter was removed 24 hours after the irrigation was stopped. In cases where the voiding trial failed, patients were recatheterized for 2 more days. Perioperative complications, the duration of catheterization, hospital days, etc. were all recorded. Follow-up was done at 1, 3, 6, 12 and 18 months at the outpatient clinic. At each follow-up visit, IPSS, QoL scores, uroflowmetry, residual volume measurements, and a PSA test were performed. TRUS was performrd in every patient at 1 month of follow-up. Cost was calculated for each of the individual procedures. It included the cost of procedure, hospital admission charges and money spent on follow-up visits and treatment of complications. It did not include the charges of the initial setup of machines and instruments.

Statistical analysis was performed between: 1) PVP and BPVP arms , 2) A1 and B1, 3) A2 and B2; using the SPSS 21 (Chicago, Il., USA) software. Student's $t$-test and the chi-squared tests were used, with $\mathrm{p}<0.05$ considered to be significant.

\section{Results}

A total of 158 patients underwent PVP or BPVP during the study period. Six patients did not meet the inclusion criteria and therefore, were excluded from the study. The preoperative characteristics mentioned in table 1 like age, IPSS score, prostatic weight, PSA values, and etc. were not statistically different between the 2 treatment modalities. Both PVP and BPVP were successfully performed on all cases except in 1 case in the BPVP arm. The cause of conversion to monopolar TURP was equipment failure. The incidence of capsular perforation and bleeding was not significantly different between the 2 arms ( $\mathrm{p}$ value: 0.51 and 0.11 , respectively). Mean operative time was similar for PVP and BPVP arms (49.5 and 51.9 minutes, $\mathrm{p}=0.13$ ) but on subgroup analysis operative duration was more for BPVP (B2) for glands $>60$ 
Table 1. Preoperative and perioperative characteristics

\begin{tabular}{|c|c|c|c|c|c|c|c|c|c|}
\hline \multirow[t]{2}{*}{ Variables } & \multirow[t]{2}{*}{ PVP } & \multirow[t]{2}{*}{ BPVP } & \multirow[t]{2}{*}{$\mathrm{p}$} & \multicolumn{3}{|c|}{$30-60 \mathrm{ml}$} & \multicolumn{3}{|c|}{$60-80 \mathrm{ml}$} \\
\hline & & & & $\mathrm{A} 1$ (PVP) & B1 (BPVP) & $\mathrm{p}$ & A2 (PVP) & B2 (BPVP) & $\mathrm{p}$ \\
\hline \multicolumn{10}{|l|}{ Preoperative } \\
\hline Number & 73 & 78 & 0.6 & 40 & 46 & 0.81 & 33 & 32 & 0.54 \\
\hline Age, year & $68(48-83)$ & $67.3(49-84)$ & 0.27 & $67.1(48-80)$ & $68.1(49-83)$ & 0.31 & $68.4(52-83)$ & $67.2(53-84)$ & 0.48 \\
\hline Prostate volume, $\mathrm{ml}$ & $64.1(33-89)$ & $62.9(34-84)$ & 0.51 & $43.7(33-58)$ & $44.1(34-58)$ & 0.23 & $76.5(63-89)$ & $75.1(62-84)$ & 0.31 \\
\hline IPSS & $25.3(20-33)$ & $24.8(21-32)$ & 0.09 & $24.9(20-32)$ & $24.4(23-32)$ & 0.91 & $25.5(22-33)$ & $26(21-30)$ & 0.76 \\
\hline QoL & $4.1(3-5)$ & $4.2(3-5)$ & 0.67 & $4(3-5)$ & $4.3(3-5)$ & 0.15 & $4.3(3-5)$ & $4.2(3-5)$ & 0.87 \\
\hline PVR, ml & $59.1(0-154)$ & $65.2(0-150)$ & 0.11 & $62.2(10-140)$ & $59.3(0-150)$ & 0.32 & $58(0-154)$ & $68.1(6-144)$ & 0.06 \\
\hline $\mathrm{Qmax}, \mathrm{ml} / \mathrm{s}$ & $5.3(3.9-9.9)$ & $4.8(4.1-10.1)$ & 0.31 & $4.9(3.9-9)$ & $5.5(4.4-10.1)$ & 0.11 & $5.7(5.2-9.9)$ & $4.7(4.1-9.4)$ & 0.41 \\
\hline PSA level, ng/ml & $1.76(0.85-3.9)$ & $1.7(0.88-3.4)$ & 0.91 & $1.5(0.85-2.7)$ & $1.5(0.88-2.6)$ & 0.41 & $2.4(1.1-3.9)$ & $2.6(0.9-3.4)$ & 0.12 \\
\hline ASA $1 \& 2$ & 25 & 28 & 0.55 & 14 & 14 & 0.67 & 11 & 14 & 0.08 \\
\hline ASA 3 & 48 & 50 & 0.12 & 28 & 29 & 0.56 & 20 & 21 & 0.61 \\
\hline Antiplatelets/anticoagulants, $\mathrm{n}$ & 19 & 19 & 0.76 & 14 & 13 & 0.22 & 5 & 6 & 0.52 \\
\hline Aspirin & 11 & 12 & & 10 & 10 & & 1 & 2 & \\
\hline Clopidogrel & 4 & 3 & & 2 & 2 & & 2 & 2 & \\
\hline Warfarin & 1 & 2 & & 1 & 1 & & 0 & 1 & \\
\hline Combination & 3 & 2 & & 1 & 0 & & 1 & 2 & \\
\hline \multicolumn{10}{|l|}{ Intra \& Postoperative } \\
\hline Bleeding, $\mathrm{n}$ & 1 & 1 & 0.51 & 0 & 0 & & 1 & 2 & 0.11 \\
\hline Capsular perforation, $\mathrm{n}$ & 1 & 2 & 0.18 & 1 & 1 & 0.22 & 0 & 1 & 0.56 \\
\hline Conversion to TURP, $\mathrm{n}$ & 0 & 1 & 0.53 & 0 & 0 & & 0 & 1 & 0.61 \\
\hline Hemoglobin drop, g/dL & $0.7(.1-1.7)$ & $0.8(0.3-1.9)$ & 0.66 & $0.4(0.1-0.8)$ & $0.4(0.2-1)$ & 0.8 & $1.1(0.7-1.7)$ & $1.3(0.8-1.9)$ & 0.73 \\
\hline Operative duration, minutes & $49.5(25-66)$ & $51.9(24-75)$ & 0.1 & $38.4(25-41)$ & $39.9(24-44)$ & 0.7 & $57.5(39-70)$ & $66.2(41-78)$ & 0.04 \\
\hline Cathetrization hours & $35.4(27-50)$ & $36.2(26-60)$ & 0.56 & $28.1(27-33)$ & $27.4(26-35)$ & 0.57 & $38.5(28-50)$ & $39.1(28-60)$ & 0.38 \\
\hline Hospital days & $2.6(2-4)$ & $2.7(2-5)$ & 0.81 & $2.1(2-4)$ & $2.2(2-4)$ & 0.9 & $3.2(2-4)$ & $3.4(2-5)$ & 0.73 \\
\hline \multicolumn{10}{|l|}{ Cost, 1, 000 INR } \\
\hline Procedure (OT + disposables) & $96.5(85-113)$ & $34.6(28-42)$ & $<0.001$ & $91.9(85-95)$ & $32.1(29-34)$ & $<0.001$ & $99.7(93-113)$ & $37.4(29-42)$ & $<0.01$ \\
\hline Hospital charges & $9.2(8-15)$ & $9.9(7-15)$ & 0.34 & $8.4(8-10)$ & $8.7(7-10)$ & 0.33 & $10.1(9-15)$ & $10.8(9-15)$ & 0.61 \\
\hline Follow-up till 18 months & $8.5(7-25)$ & $8.7(7-23)$ & 0.79 & $7.9(7-10)$ & $8.1(7-10)$ & 0.46 & $9.1(8-11)$ & $9.2(7-11)$ & 0.39 \\
\hline
\end{tabular}

ASA = American Society of Anesthesiologists, OT $=$ operation theatre.

Table 2. Indication and perioperative management of OA therapy

\begin{tabular}{|c|c|c|c|c|}
\hline Type of OA & Indication & $\operatorname{PVP}(\mathrm{n})$ & $\operatorname{BPVP}(n)$ & Management \\
\hline Aspirin & myocardial infarction & 9 & 12 & aspirin continued \\
\hline Clopidegrol & myocardial infarction & 2 & 2 & $\begin{array}{l}\text { clopidegrol continued in all except } 1 \text { where it was } \\
\text { discontinued } 5 \text { days prior to surgery and restarted } \\
\text { again after } 24 \text { hours }\end{array}$ \\
\hline Aspirin + clopidegrol & chronic atrial fibrillation & 1 & 0 & $\begin{array}{l}\text { aspirin was continued but clopidegrol was discon- } \\
\text { tinued } 5 \text { days prior to surgery and restarted again } \\
\text { after } 24 \text { hours }\end{array}$ \\
\hline \multirow[t]{2}{*}{ Warfarin } & deep vein thrombosis & 1 & 1 & bridge therapy \\
\hline & mitral valve prosthesis & 0 & 1 & \\
\hline
\end{tabular}

$\mathrm{OA}=$ Oral anticoagulation. Bridge therapy: Warfarin stopped and i.v. unfractionated heparin started 5 days before procedure; Target INR 1 day before surgery: < 1.5, Last dose given 6 hours before surgery and restarted after 6 hours or on the evening of the surgery. Warfarin started in the morning following surgery and heparin stopped once therapeutic INR achieved.

$\mathrm{ml}$, although, the difference was only marginally significant $(\mathrm{p}=0.04)$. Catheterization time and hospital days were almost similar in both the arms as was the drop in hemoglobin ( $\mathrm{p}=0.56,0.81$, and 0.66 , respectively). The cost of the procedure (operation theatre charges + disposables) was significantly more in PVP arm $(\mathrm{p}<0.01)$. 
Table 3. Complications

\begin{tabular}{|c|c|c|c|c|c|c|c|c|c|}
\hline \multirow[t]{2}{*}{ Complication } & \multirow{2}{*}{$\begin{array}{c}\mathrm{PVP}(\mathrm{n}) \\
\mathrm{n}(\%)\end{array}$} & \multirow{2}{*}{$\begin{array}{l}\operatorname{BPVP}(\mathrm{n}) \\
\mathrm{n}(\%)\end{array}$} & \multirow[t]{2}{*}{$\mathrm{p}$} & \multicolumn{3}{|c|}{$30-60 \mathrm{ml}$} & \multicolumn{3}{|c|}{$60-80 \mathrm{ml}$} \\
\hline & & & & $\mathrm{A} 1 \mathrm{n}(\%)$ & B1 n (\%) & $\mathrm{p}$ & $\mathrm{A} 2 \mathrm{n}(\%)$ & B2 n (\%) & $\mathrm{p}$ \\
\hline \multicolumn{10}{|l|}{ Early } \\
\hline Clot retention & $1(1.4)$ & $2(2.6)$ & 0.21 & 0 & 0 & & $1(3.0)$ & $2(6.2)$ & 0.15 \\
\hline Recatheterization & $2(2.7)$ & $2(2.6)$ & 0.95 & $1(2.5)$ & $1(2.2)$ & 0.96 & $1(3.0)$ & $1(3.1)$ & 0.33 \\
\hline Urinary tract infection & $4(5.5)$ & $3(3.8)$ & 0.10 & $2(5.0)$ & $1(2.2)$ & 0.08 & $2(6.1)$ & $2(6.2)$ & 0.72 \\
\hline Dysuria & $7(9.6)$ & $8(10.2)$ & 0.55 & $2(5.0)$ & $3(6.5)$ & 0.16 & $5(15.1)$ & $5(15.6)$ & 0.32 \\
\hline Transient incontinence & $1(1.4)$ & $1(1.3)$ & 0.69 & $1(2.5)$ & $1(2.2)$ & 0.47 & 0 & 0 & \\
\hline \multicolumn{10}{|l|}{ Late } \\
\hline Stricture & $1(1.4)$ & $2(2.6)$ & 0.13 & $1(2.5)$ & $1(2.2)$ & 0.11 & 0 & $1(3.1)$ & 0.41 \\
\hline Bladder neck contracture & $2(2.7)$ & $1(1.3)$ & 0.22 & $2(5.0)$ & $1(2.2)$ & 0.20 & 0 & 0 & \\
\hline
\end{tabular}

There was no requirement of blood transfusion in both the main arms although, there was 1.4 and $2.6 \%$ rate of clot retention in PVP and BPVP, respectively $(\mathrm{p}=0.09)$. The re-hospitalization rate due to secondary hemorrhage was similar and 1 patient in each group was readmitted after 5 days of discharge. Dysuria occurred in 9.6 and $10.2 \%$ of patients in PVP and BPVP, respectively. It subsided in all but 2 cases with anticholinergic drugs within 6 weeks. In the rest of the 2 cases, it persisted for nearly 6 months (table 3).

At 1-month follow-up, significant improvements in all the measured variables (Qmax, IPSS and QoL scores) were noted in both the PVP and BPVP groups (table 3). The differences remained stable and significant in all regards at the 3, 6, 12 and 18-month follow-up. At the 1 -month evaluation of prostate volume by TRUS there were similar improvements for patients from both arms, consisting of a decrease in prostate volume of 68.7 and $69.5 \%$ for PVP and BPVP, respectively. The PSA level measured at follow-up months also displayed a similar response in the 2 arms (table 4). These improvements in the above mentioned variables were similar in subgroup analysis suggesting that both PVP and BPVP were effective treatment options.

\section{Discussion}

A variety of vaporization procedures using different energy sources have been described [8]. Long-term data and the number of randomized controlled trials for procedures other than PVP are limited $[9,10]$. Numerous studies have proven that PVP has a similar or greater efficacy to TURP in terms of Qmax, post void residue (PVR), QoL and IPSS and offers several advantages over TURP in terms of blood loss, transfusion, capsular perforation, transurethral resection syndrome, catheterization time and hospital stay [11-13]. Although, the $180 \mathrm{~W}$ PVP system has been introduced with success in many centers in the United States and Europe, 120 W PVP system is still safe and efficacious for managing BPH [11-13]. Similarly, some recent series have suggested excellent hemostatic efficiency of BPVP as compared to TURP and similar short-term functional outcomes [14, 15]. Long-term follow-up of BPVP is not available at present, but there are quite a few studies with short- and mid-term follow-up that show it is a safe and effective procedure $[6,16]$. Both photoselective and bipolar vaporization are carried out in normal saline, and both have the advantage of concomitant vaporization and coagulation. These properties do not alter the visual characteristics of the tissues, enabling the surgeon to differentiate between the adenomatous tissue, the muscular fibres of the prostatic capsule and the anatomical boundaries of the operating area with increased accuracy. Due to the lack of bleeding, visibility remains excellent throughout the procedure. The mean drop of hemoglobin was $0.7 \mathrm{~g} / \mathrm{dL}$ for the PVP arm and this is in accordance with the studies performed by Ansari and Lukas et al. [12, 13] who in their studies have also reported less blood loss for PVP. Similarly for BPVP arm, the mean drop of hemoglobin was near 0.8 $\mathrm{g} / \mathrm{dL}$ and therefore, no blood transfusion was required. Geavlete and Kranzbu"hler et al. [5, 17], in their studies have also reported $0 \%$ transfusion rate for BPVP. In our 
Table 4. Follow-up parameters

\begin{tabular}{|c|c|c|c|c|c|c|c|c|c|}
\hline \multirow[t]{2}{*}{ Parameters } & \multirow[t]{2}{*}{ PVP } & \multirow[t]{2}{*}{ BPVP } & \multirow[t]{2}{*}{$\mathrm{p}$} & \multicolumn{2}{|c|}{$30-60 \mathrm{ml}$} & \multirow[b]{2}{*}{$\mathrm{p}$} & \multicolumn{3}{|c|}{$60-80 \mathrm{ml}$} \\
\hline & & & & $\mathrm{A} 1$ (PVP) & B1 (BPVP) & & A2 (PVP) & B2 (BPVP) & $\mathrm{p}$ \\
\hline IPSS & - & & & & & & & & \\
\hline 3 month & $4.8(1-21)$ & $5.1(1-21)$ & 0.26 & $4.9(1-20)$ & $5.3(1-21)$ & 0.08 & $4.4(1-21)$ & $4.6(1-21)$ & 0.17 \\
\hline 6 month & $4.0(0-21)$ & $4.2(1-20)$ & 0.29 & $4.2(1-21)$ & $4.4(2-20)$ & 0.1 & $3.8(0-20)$ & $4.0(1-19)$ & 0.2 \\
\hline 12 months & $3.9(0-19)$ & $4.1(0-20)$ & 0.19 & $4.1(1-19)$ & $4.1(1-19)$ & 0.16 & $3.8(0-19)$ & $3.6(0-20)$ & 0.16 \\
\hline 18 months & $3.9(0-19)$ & $4.0(1-19)$ & 0.22 & $3.8(0-19)$ & $4.1(1-18)$ & 0.08 & $3.9(1-18)$ & $3.7(1-19)$ & 0.15 \\
\hline 1 month & $21.4(10.1-30.4)$ & $20.9(9.9-30.2)$ & 0.37 & $20.9(10.1-29.4)$ & $20.1(9.9-28.9)$ & 0.21 & $21.9(11.9-30.4)$ & $21.6(11.2-30.2)$ & 0.27 \\
\hline 3 months & $21.9(10.0-31.2)$ & $21.3(10.0-31.9)$ & 0.35 & $21.7(10.5-30.9)$ & $21.1(10.0-30.7)$ & 0.26 & $22.2(10.0-31.2)$ & $21.8(11.2-31.9)$ & 0.25 \\
\hline 6 months & $22.3(10.0-32.2)$ & $22.1(10.1-32.3)$ & 0.31 & $21.6(10.6-31.4)$ & $21.7(11.2-32.3)$ & 0.31 & $22.7(10.0-32.2)$ & $22.6(10.1-32.2)$ & 0.34 \\
\hline 12 months & $22.8(9.8-33.3)$ & $22.4(10.5-32.9)$ & 0.33 & $22.4(9.8-3.3)$ & $22.1(11.1-32.8)$ & 0.29 & $23.2(9.9-33.0)$ & $22.7(10.5-32.9)$ & 0.3 \\
\hline 18 months & $22.8(10.1-34.1)$ & $22.5(10.1-33.5)$ & 0.35 & $22.4(10.1-33.6)$ & $22.2(12.1-33.5)$ & 0.23 & $23.2(10.6-34.1)$ & $23.1(10.1-33.1)$ & 0.28 \\
\hline \multicolumn{10}{|l|}{ QoL } \\
\hline 1 month & $2.1(1-5)$ & $2.0(1-5)$ & 0.09 & $2.2(1-5)$ & $2.1(1-5)$ & 0.33 & $2.1(1-4)$ & $1.9(1-5)$ & 0.49 \\
\hline \multicolumn{10}{|l|}{ PVR, ml } \\
\hline 1 month & $30.5(5-130)$ & $35(10-125)$ & 0.56 & $30.1(5-75)$ & $36.5(15-120)$ & 0.11 & $31.0(7-130)$ & $34.6(10-125)$ & 0.39 \\
\hline 3 months & $31(0-110)$ & $35.5(7-125)$ & 0.45 & $31.0(0-100)$ & $35.0(7-110)$ & 0.16 & $31.0(0-110)$ & $36.0(10-125)$ & 0.35 \\
\hline 6 months & $27.1(0-90)$ & $30.5(0-95)$ & 0.5 & $27.0(5-85)$ & $30.1(5-95)$ & 0.11 & $29.0(0-90)$ & $31.0(0-75)$ & 0.4 \\
\hline 12 months & $25.5(0-75)$ & $27.1(0-87)$ & 0.49 & $23.9(0-72)$ & $28.0(0-85)$ & 0.17 & $26.0(7-75)$ & $25.1(0-87)$ & 0.37 \\
\hline 18 months & $26.1(0-80)$ & $26.7(0-82)$ & 0.51 & $25.5(0-77)$ & $26.5(5-82)$ & 0.13 & $25.9(0-80)$ & $26.7(0-76)$ & 0.33 \\
\hline \multicolumn{10}{|l|}{$\mathrm{PSA}, \mathrm{ng} / \mathrm{ml}$} \\
\hline 3 months & $1.5(0.21-2.77)$ & $1.6(0.27-2.81)$ & 0.48 & $1.5(0.21-1.67)$ & $2.0(0.27-2.56)$ & 0.33 & $2.1(0.56-2.77)$ & $2.5(0.49-2.81)$ & 0.51 \\
\hline 6 months & $1.5(0.20-1.97)$ & $1.6(0.19-2.00)$ & 0.39 & $1.5(0.20-2.10)$ & $1.8(0.19-2.01)$ & 0.35 & $1.8(0.71-1.97)$ & $1.9(0.65-2.00)$ & 0.45 \\
\hline 12 months & $1.5(0.19-1.94)$ & $1.5(0.16-1.81)$ & 0.43 & $1.4(0.19-1.62)$ & $1.6(0.16-1.99)$ & 0.29 & $1.8(0.76-1.94)$ & $1.6(0.59-1.81)$ & 0.52 \\
\hline 18 months & $1.5(0.17-1.87)$ & $1.5(0.16-1.82)$ & 0.39 & $1.2(0.17-1.32)$ & $1.5(0.16-1.65)$ & 0.22 & $1.7(0.69-1.87)$ & $1.7(0.60-1.82)$ & 0.49 \\
\hline $\begin{array}{l}\text { Prostate volumn, } \\
\mathrm{ml} \text { (at } 1 \text { month) }\end{array}$ & $20.1(10-31)$ & $19.7(11-35)$ & 0.19 & $14.5(10-24)$ & $13.5(11-23)$ & 0.34 & $23.9(14-31)$ & $24.6(12-35)$ & 0.29 \\
\hline
\end{tabular}

study, there were 26 and $24.4 \%$ patients on antiplatelet therapy in PVP and BPVP arms, respectively (table 2). In both the arms there was no significant bleeding complication in such patients. In earlier trials, PVP has already proved that it is indeed helpful in patients who are on anticoagulants as this laser is selectively absorbed by hemoglobin, within the prostatic tissue and thus helps in removal of the tissue by rapid photothermal vaporization of the heated intracellular water [18-20]. However, there are not many studies in literature regarding the use of BPVP in patients receiving antiplatelet/anticoagulants barring a few like Kranzbuhle and Delongchamps et al. who in their studies reported that BPVP was safe in patients receiving anticoagulants, although, the majority of these patients were on antiplatelet drugs rather than on oral anticoagulants $[17,21]$. This quality of BPVP is perhaps because significant high energy is contained within the plasma layer and is released locally on contact of the tissue to a more specific point with less collateral spread. Additionally, bipolar energy could result in significantly more depth of coagulation as suggested by some studies on bipolar TURP $[22,23]$.

There were no significant intraoperative complications in both the study arms and the perioperative outcomes like irrigation time, catheterization time and time to discharge were similar in both the groups. Operative time was also same in both the main groups, although on comparison between the subgroups, the duration was more for BPVP when the prostate size was more than 60 $\mathrm{ml}$ (A2 vs. B2: 57.5 vs. 65.8 minutes). The reason for this could be the unavoidable pauses in the plasma activation process, every 8-12 s, to prevent the bipolar generator from overheating. This perhaps affects the fluency of the BPH tissue ablation specially for larger sized glands. This drawback is somewhat counterbalanced by the fact that tissue vaporization occurs both with the passive as 
well as with the active movement of the electrode. Furthermore, with the development of the new ESG-400 bipolar generator (Olympus Europe, Hamburg, Germany) vaporization time can be further reduced by approximately $22 \%$. This is because the new generator permits a continuous plasma activation process without any pause and that too at substantially lower currents $(200 \mathrm{~W}$ for vaporization and $120 \mathrm{~W}$ for coagulation) [24]. The recatheterization rate in our study was 2.7 and $2.6 \%$ for PVP and BPVP, respectively. All cases could void after their second voiding trial after 2 days. The reduction in prostate volume at the end of the first month was about $69 \%$ in both the arms and is similar to that reported for other series [14]. There were significant improvements in Qmax, IPSS and QoL scores in both the groups initially as well as at 18 months, suggesting the durable results of both the procedures. No significant differences were found in the occurrence of short- as well as long-term complications like clot retention, secondary hemorrhage, re-operation, stricture formation and bladder neck contracture. These results were also comparable to those reported in other studies on PVP and BPVP [5-7, 10-13, $16,17,25]$.

There was a major difference between the 2 arms in terms of expenditure [PVP vs. BPVP: 96500 Indian Ruppee (INR) vs. 34600 INR]. Stovsky et al. [26] in their study did a cost analysis comparing PVP with other minimally invasive therapies and reported that most costs at all time were due to the initial procedural intervention, whereas only $6-30 \%$ of it was related to re-treatment or treatment of complications. This is true for our study as well, wherein the hospital charges, cost of follow-up visits and of treatment failure was similar in both the groups. The difference was mainly in the cost of disposables and theatre charges, but that was fairly substantial. Preliminary cost analysis studies on KTP laser prostatectomy are in favor of PVP when compared to TURP. This is mainly due to considerably shorter hospital stay, length of catheterization and fewer complications [27]. This could be true when PVP is compared with TURP but not when it is compared to BPVP. As shown in this study as well as in others, the hospital days, catheterization time, complication rates, re-intervention rate and improvement in symptom scores are comparable to those reported for PVP $[5-7,16,17,25]$. PVP may potentially provide cost savings for patients on anticoagulants for whom bleeding risk and management of anticoagulation therapy can complicate treatment but the data for this study showed equal safety profile for both BPVP and PVP in patients on anticoagulants.
The level of evidence supporting safety and efficacy of green light laser is much higher than for BPVP. A meta-analysis with pooled results from 9 different randomized controlled trials and 889 study participants followed-up for 6-36 months was published recently [28]. Although BPVP has shown promising results, they still need to be confirmed in more randomized trials and in studies with longer follow-up. Nevertheless, in countries like ours where finances are an issue, and resources are limited; BPVP with its equal safety and efficacy profile may stand as a better alternative to PVP in the future. The major reason being that for the latter, the initial setup cost is more and the recurring high cost of a new laser fiber for every single procedure is unavoidable.

The main drawback of the study is that it is a retrospective single center study with only mid-term followup and therefore a multicenter trial with longer follow-up would be definitely more informative.

\section{Conclusion}

Both PVP and BPVP were safe and effective procedures in men with $\mathrm{BPH}$ including those on anticoagulants. BPVP has the additional advantage of being significantly cheaper although, multicenter trials with long follow-up are needed for bipolar vaporization to supersede photoselective vaporization with green light. 


\section{References}

1 Mohanty NK, Vasudeva P, Kumar A, Prakash S, Jain M, Arora RP: Photoselective vaporization of prostate vs. transurethral resection of prostate: a prospective, randomized study with one year follow-up. Indian J Urol 2012; 28:307-312.

2 Ruszat R, Wyler S, Forster T, Reich O, Stief CG, Gasser TC, Sulser T, Bachmann A: Safety and effectiveness of photoselective vaporization of the prostate (PVP) in patients on ongoing oral anticoagulation. Eur Urol 2007;51:1031-1041.

3 Bachmann A, Schurch L, Ruszat R, Wyler SF, Seifert HH, Müller A, Lehmann K, Sulser $\mathrm{T}$ : Photoselective vaporization (PVP) versus transurethral resection of the prostate (TURP): a prospective bi-centre study of perioperative morbidity and early functional outcome. Eur Urol 2005;48:965-971.

4 Oelke M, Alivizatos G, Emberton M, Gravas S, Madersbacher S, Michel M, Nordling J, Rioja Sanz C, de la Rosette J: Guidelines on benign prostatic hyperplasia; in Parsons KF, Irani J, Chapple CR, Fall M, Hanus T, Llorente Abarca C, Loch T, Mitropoulos D, N'Dow J, Schmid HP, Sylvester R (eds): European Association of Urology Pocket Guidelines. Arnhem: European Association of Urology, 2009, pp90-97.

5 Geavlete B, Multescu R, Dragutescu M, Jecu M, Georgescu D, Geavlete P: Transurethral resection (TUR) in saline plasma vaporization of the prostate vs standard TUR of the prostate: 'the better choice' in benign prostatic hyperplasia? BJU Int 2010;106:16951699.

6 Geavlete B, Georgescu D, Multescu R, Stanescu F, Jecu M, Geavlete P: Bipolar plasma vaporization vs monopolar and bipolar TURP - a prospective, randomized, long-term comparison. Urology 2011;78:930-935.

7 Zhang SY, Hu H, Zhang XP, Wang D, Xu KX, Na YQ, Huang XB, Wang XF: Efficacy and safety of bipolar plasma vaporization of the prostate with 'button-type' electrode compared with transurethral resection of prostate for benign prostatic hyperplasia. Chin Med J (Engl) 2012;125:3811-3814.

8 Herrmann TR, Liatsikos EN, Nagele U, Traxer O, Merseburger AS: EAU guidelines on laser technologies. Eur Urol 2012;61:783795.

9 Cornu JN, Ahyai S, Bachmann A, de la Rosette J, Gilling P, Gratzke C, McVary K, Novara G, Woo H, Madersbacher S: A systematic review and meta-analysis of functional outcomes and complications following transurethral procedures for lower urinary tract symptoms resulting from benign prostatic obstruction:an update. Eur Urol 2015; 67:1066-1096.
10 Teng J, Zhang D, Li Y, Yin L, Wang K, Cui X, $\mathrm{Xu}$ D: Photoselective vaporization with the green light laser vs transurethral resection of the prostate for treating benign prostate hyperplasia: a systematic review and meta-analysis. BJU Int 2012;111:312-323.

11 Capitan C, Blazquez C, Martin MD, Hernández V, de la Peña E, Llorente C: GreenLight HPS 120-W laser vaporization versus transurethral resection of the prostate for the treatment of lower urinary tract symptoms due to benign prostatic hyperplasia: a randomized clinical trial with 2-year follow-up. Eur Urol 2011;60:734-739.

12 Al-Ansari A, Younes N, Sampige VP, Al-Rumaihi K, Ghafouri A, Gul T, Shokeir AA: GreenLight HPS 120-W laser vaporization versus transurethral resection of the prostate for treatment of benign prostatic hyperplasia: a randomized clinical trial with midterm followup. Eur Urol 2010;58:349-355.

13 Lukacs B, Loeffler J, Bruyere F, Blanchet P, Gelet A, Coloby P, De la Taille A, Lemaire P, Baron JC, Cornu JN, Aout M, Rousseau H, Vicaut E: Photoselective vaporization of the prostate with GreenLight 120 -W laser compared with monopolar transurethral resection of the prostate: a multicenter randomized controlled trial. Eur Urol 2012;61:11651173.

14 Robert G, de la Taille A, Herrmann T: Bipolar plasma vaporization of the prostate: ready to replace GreenLight? A systematic review of randomized control trials. World J Urol 2015; 33:549-554.

15 da Silva RD, Bidikov L, Michaels W, Gustafson D, Molina WR, Kim FJ: Bipolar energy in the treatment of benign prostatic hyperplasia: a current systematic review of the literature. Can J Urol 2015;22(Suppl 1):30-44.

16 Hon NH, Brathwaite D, Hussain Z, Ghiblawi S, Brace H, Hayne D, Coppinger SW: A prospective, randomized trial comparing conventional transurethral prostate resection with PlasmaKinetic vaporization of the prostate: physiological changes, early complications and long-term followup. J Urol 2006; 176:205-209.

17 Kranzbühler B, Wettstein MS, Fankhauser CD, Grossmann NC, Gross O, Poyet C, Largo R, Fischer B, Zimmermann M, Sulser T, Müller A, Hermanns T: Pure bipolar plasma vaporization of the prostate: the Zurich experience. J Endourol 2013;27:1261-1266.

18 Reich O, Bachmann A, Siebels M, Hofstetter A, Stief CG, Sulser T: High power $(80 \mathrm{~W})$ potassium-titanyl-phosphate laser vaporization of the prostate in 66 high risk patients. $\mathrm{J}$ Urol 2005;173:158-160.
19 Sandhu JS, Ng CK, Gonzalez RR, Kaplan SA, Te AE: Photoselective laser vaporization prostatectomy in men receiving anticoagulants. J Endourol 2005;19:1196-1198.

20 Pawan V, Anop K, Niraj K, Biswajit N, Punita R, Rajendra A, Nayan M: Safety and efficacy of photoselective vaporization of prostate in patients receiving anticoagulants. Minerva Urol Nephrol 2013;65:189-195.

21 Delongchamps NB, Robert G, de la Taille A, Haillot O, Ballereau C, Saussine C, Kleinclauss F, Azzouzi AR, Lukacs B, Dumonceau O, Fourmarier M, Devonec M, Descazeaud A: Surgical management of BPH in patients on oral anticoagulation: transurethral bipolar plasma vaporization in saline versus transurethral monopolar resection of the prostate. Can J Urol 2011;18:6007-6012.

22 Huang X, Wang XH, Wang HP, Qu LJ: Comparison of the microvessel diameter of hyperplastic prostate and the coagulation depth achieved with mono- and bipolar transurethral resection of the prostate. A pilot study on hemostatic capability. Scand J Urol Nephrol 2008;42:265-268.

23 Huang X, Wang L, Shi HB, Zhang XJ, Yu $\mathrm{ZY}$ : Bipolar transurethral resection of prostate causes deeper coagulation depth and less bleeding than monopolar transurethral prostatectomy. Urology 2012;80:1116-1120.

24 Geavlete B, Stanescu F, Moldoveanu C, Geavlete P: Continuous vs conventional bipolar plasma vaporisation of the prostate and standard monopolar resection: a prospective, randomised comparison of a new technological advance. BJU Int 2014;113:288-295.

25 Stovsky MD, Griffiths RI, Duff SB: A clinical outcomes and cost analysis comparing photoselective vaporization of the prostate to alternative minimally invasive therapies and transurethral prostate resection for the treatment of benign prostatic hyperplasia. J Urol 2006;176(4 Pt 1):1500-1506.

26 Alivizatos G, Skolarikos A: Photoselective vaporization of the prostate. Review of cost implementation to BPH treatment. Prostate Can Prostatic Dis 2007;10:S15-S20.

27 Thangasamy IA, Chalasani V, Bachmann A, Woo HH: Photoselective vaporisation of the prostate using $80-\mathrm{W}$ and $120-\mathrm{W}$ laser versus transurethral resection of the prostate for benign prostatic hyperplasia: a systematic review with meta-analysis from 2002 to 2012 . Eur Urol 2012;62:315-323. 